\title{
Correction to: The role played by viscoelasticity in the bulk material during the propagation of a dynamic crack in elastomers
}

\author{
Vasudevan Kamasamudram (D) Michel Coret $\cdot$ Nicolas Moës
}

Accepted: 8 July 2021 / Published online: 27 July 2021

(C) Springer Nature B.V. 2021

Correction to: Int J Fract

https://doi.org/10.1007/s10704-021-00561-8

The original online version of this article was revised due to typesetting mistakes made regarding the captions of the figures 12 and 13.
Publisher's Note Springer Nature remains neutral with regard to jurisdictional claims in published maps and institutional affiliations.

The original article can be found online at https:// doi.org/10.1007/s10704-021-00561-8.

V. Kamasamudram $(\square) \cdot$ M. Coret · N. Moës GeM Institute, UMR CNRS 6183, Centrale Nantes, 1 rue de la Noë, Nantes 44321, France

e-mail: vasudevan.kamasamudram@ec-nantes.fr

M. Coret

e-mail: michel.coret@ec-nantes.fr

N. Moës

e-mail: nicolas.moes@ec-nantes.fr

N. Moës

Institut Universitaire de France, Paris, France 